\title{
The Role of Television Video in Emerging a Social Movement: A Study of Information Environment
}

\author{
Chuan Y. Hsu \\ Department of communication, Tamkang University, Yingzhuan Rd, Tamsui District, New Taipei City, 25157, Taiwan
}

\begin{abstract}
This paper is about studying the role of visual materials in constructing information environment in Taiwan. In general, the information environment is the pluralization of life-world that creates the distinctive opportunities and pathologies of modern life. Based on the evidence of case study, I discussed the visual effects of computer-mediated communication (CMC) in information environment. In theory, a common issue concerning with the Information Society theorists is: if virtual community could be viewed as a form of social collectiveness in the Information Society, then, what is the role of information has played in attaining a community. Toward this end, the paper will be composed of two parts. In the first half, with reference to information theory and social movement studies, I demonstrate the promise of information technology for upholding virtual movements. Based upon theoretical concepts and empirical findings, then, I survey a visual-text mixed event in Taiwan. Furthermore, in terms of theoretical concern, how the information environment contributes to the discussion of social movement is presented in conclusion section. The empirical data were collected from electronic content stored in PTT computer hosting service. These data were analyzed by using the qualitative method. I argue that visual material is a part of framing the everyday activities into the environment. The task of visual-text information is to reason a ground of cultural identity. The virtual community becomes an unique access for pluralizing knowledge in a society. Through setting the visual-text of information environment, the use of the information itself constituted and constructed a web event.
\end{abstract}

\section{Introduction}

For the Taiwanese, the baseball is an important symbol for constituting national imaginary. In this study, I survey one of major Taiwanese virtual movement to deliberate the relationship between information communication technology (ICT) and constructing an imagined community. In 2008, one of professional baseball teamsDmedia T-Rex, involved a match fixing scandal. The baseball fans launched a virtual movement to criticize the baseball's managerial system. The Internet is becoming increasingly important as a tool used by social movements in this case. It is used for a variety of purposes by these movements. The Website may be employed as a place to demonstrate the purposes of social movements. News group may serve as a recruitment channel for membership in social movements. However, can this sort of mediated campaign substitute for "real" social ally? This debate, therefore, raises fundamental issues for deliberating about the roles of information communication technology (ICT) in the arena of communication studies.

Basically, in this study, the virtual movement is viewed as an important communication pattern which may transform the social constitution in the Information Society. Then, a theoretical concern is, do the virtual movement may constitute a social space by way of recasting a cultural symbol? The following essay will concentrate on the relationship between the Internet and social movements. The first section emphasizes the theoretical differences between new social movements and virtual movements. The second section employs empirical studies to contribute to our understanding of the role of new communication technologies in promoting social communication. This case study begins with a discussion of the theoretical propositions of Internet social movements' purposes and resources for mobilization. I then survey the text of virtual movement. The empirical data were collected from electronic artifacts stored in PTT computer hosting service. I will argue that the virtual movement fabricates an event by the ordinary user, and the affective connections resources the internet mobilization by appropriating the national imaginaryimages of baseball players. The virtual movement becomes a unique space for popularizing knowledge in the Information Society. In other words, the virtual movement is not only a resistance form but a place for localizing expert's knowledge.

\section{The information environment}

The information environment is the field of information practice. The environment, in this study, refers to a social space constituted by the computer-mediated communication. For purpose of constructing a social aggregation, understanding how to connect with their memberbase is the main task. The task of virtual mobilization is to set up the emotional connection, which can achieve the cultural expressiveness. The utilization of CMC can be expected to generate new information environment a networks or virtual extensions, problematic the usage of information and the constitution of community [1]. In this case, generally stated, virtual movements employ e-mail or on-line chat rooms to enable user to associate with others. For instance, in a study of a British environmental protection group, one researcher found out that e-mail is a useful facility to share mutual experiences [2]. For the sake of creating an effective communication pattern,

*Corresponding Author: Dr. Chuan Y. Hsu, Department of communication, Tamkang University, Yingzhuan Rd, Tamsui District, New Taipei City, 25157 Taiwan; E-mail: 093663@mail.tku.edu.tw

Citation: Hsu CY (2015) The Role of Television Video in Emerging a Social Movement: A Study of Information Environment. Int J Journalism Mass Comm 2: 109. doi: http://dx.doi.org/10.15344/2349-2635/2015/109

Copyright: (c) 2015 Hsu. This is an open-access article distributed under the terms of the Creative Commons Attribution License, which permits unrestricted use, distribution, and reproduction in any medium, provided the original author and source are credited. 
in contrast with mode of mass communication, computer mediated communication (CMC) holds a crucial position. As Coleman [3] observes, "many-to-many communication permits experiential knowledge to return to its rightful place in the hierarchy of social communication. It allows people to discuss on the basis of what they know from doing as well as from contemplation"(p.208). Precisely, information is more likely to be an effective tool in mobilizing members without personal contact, and this differentiates information movements from traditional movements. Pickerill (2001) argued, "it has been illustrated that it is possible to mobilize those who are already within the movement networks (or those who are cognate) using CMC without face-to-face contact"(p.164). Furthermore, virtual movements can create a hybrid social surrounding in which traditional or mediated forms coexist. As Sypher and Collins argue:

The technology can function to replace or displace traditional community or social activity much like any other activity. It can also function to provide people with alternative communities that only exist by virtue of the technology-forms of community that do not exist in unmediated environments [5].

In short, in order to review how virtual movement functions, the way in which the movement groups use the new communication strategies created by information to connect members will be an important criterion to consider. Moreover, in order to understand the character of virtual association, the electronic artifact from the users also is a locus, that allows us to understand a "textualized" space in terms of symbolic communication practices [6].

\section{Everyday practices and Social movements}

My approach views social movement as about the project of everyday life rather than social unit of epistemological knowledge. Due to the emergence of identity-based movements or new social movement, organization the organizer of information and knowledge is under challenge [7]. One study of a Palestinian refugee camp indicates that the diasporic fragmentation of refugees has become an essential character of the Palestinian resistance movement. In Refugees, Resistance and Identity, Peteet [8] writes, "fragmentation, with its multiple geographic and cultural sites of exile, has fostered in Palestinians transnational identities. The Palestinians are seeking of common ground on a variety of levels of affiliation"(p.185). In other words, a de-centralized organization of social movements is appearing. The discussions on the virtual moment might shed a new light on the increasingly complicated phenomena of social movements. In this article, I argue that the identity is the function of spatial practice.

Traditional social movement theories focus on the role of organizations in political mobilization, and the practical accomplishment of converting the established order; on the other hand, many new social movements insist on the struggle for cultural identities. In definition, compared with traditional social movements, British sociologist Giddens regards the new social movements as "life politics" [9]. Giddens urges that social movements may be seen as an important constitution of reflexivity in modern society. However, due to the proliferation of communication media, communication technologies might become a new base for reshaping collective action rather than the social reflectivity. In the study of collective action, the purpose of studying cultural identity of social movement is about exploring the creation of luminal place.
In other words, instead of centralized organization in social movements, cultural movements focus on a more flexible form of organizing for mobilization. In terms of practical purposes, cultural movement put more emphasis on the struggle for cultural identities than substantial political community. In summary, from the perspective of social movement, the communication of social aggregation is about to set up a communication site for the extending the activities of social imaginaries.

\section{Information movements}

The main effect of the new technologies in social movements has been the creation of a naive form of resistance. From the resistance in a manner of providing texts to horizontal networking or connecting with similar interest groups, ICT plays a significant role in disseminating purposive messages. In addition, this new form of social movement induces the theorists of social movements to reconsider the mobilization pattern of social movement used by these movements.

This is not to say that by utilizing the potential of the Internet, the marginal could somehow magically and suddenly realign the relationship between the dominant and the marginal, but it is possible to enter into a dialog where the dominant cannot systematically drown out or silence the marginal [10].

An ethnographic analysis also suggests that the uses of the Internet extend the life-world, and upholds the public sphere or public culture to the colonized world that has been undermined by commercial and political forces. As Bakardjieva and Smith [11] argue, "In the absence of such a project [a democratic encounter project], users will be forced to give up to the totalizing stabilization of the consumption possibilities (e-commerce, Web TV, etc) foisted on them by the dominant economic and political rationality"(p.81).

\section{Methodology}

In order to analyse a variety of newspaper reports and compare them by visualising them, we can use various qualitative research methods. My research is based on an analysis of qualitative research (a qualitative study) of 890 newspaper reports by two methods: a critical analysis of visual communication [10], and the fallacy of a "pictorial turn" [1].

In addition to the fact that the Internet opens a voice channel for social movements, the Internet used by nationalist movements reconnect groups that have been socially segregated and dispersed. In the Philippines, a cyber community named Cyber Barangay unifies diversified social groups by way of subcultures; for instance, basketball and jokes. A Filipino scholar Sy [12] indicates, " information technology brings to the fore the reality of imagined Filipino communities' whose nationhood is otherwise undermined by regionalism and ethnic loyalties"(p.301). In addition to building virtual communities, a civic movement organization can try to use the Internet to set up the agenda for policy deliberations, which is expected to bring about a deliberative communication to substitute for the representative democracy [3].

Washbourne [2] argues that Internet is creating a new form of social movement, networking through horizontal communication, which is different from the pattern of mobilization used in the in process of 
Citation: Hsu CY (2015) The Role of Television Video in Emerging a Social Movement: A Study of Information Environment. Int J Journalism Mass Comm 2: 109. doi: http://dx.doi.org/10.15344/2349-2635/2015/109

raising the awareness of the public. Urging this new concept of translocalism, he considers that decentralized communication networks, which are connected by regional or peripheral environmental protection groups, transcend central organization. As a result, they constitute new patterns of participation in social movements. He argues:

The expansion of IT use arose in relation to a widely shared conception that IT could not only help FoE [Friend of Earth] influence public policy and environmental debate but also was congruent with FoE's globalist values. I call that action, arising in specific, local circumstance but able to mobilize resources to go beyond the merely local, trans-localism[2].

According to these authors, the rise of the Internet has transformed the traditional formats of social mobilization, and should lead us to reconsider the role of Internet in social movements. To summarize, because of the accessibility of ICT, the Internet is becoming important resources for social movement groups.

Various authors claim that the new communication technologies are changing the style and momentum of social movements. In contrast to traditional social movements, the Internet creates awareness of social movement among the public with lower costs. Moreover, due to the Internet's ability to allow interaction between the public and the social movements' leaders, a movement's organization could transform itself from a mobilization machine to an agendasetting one. For a democratic society, moreover, the web-based virtual movement might be expected to bring about a society of democracy in terms of participatory deliberation, which sheds a light on a new way to achieve social space in terms of rethinking the criterion of social norms.

\section{The resources of information movement}

In order to challenge the commercialized media, information movements try to create their own channel of communication. First of all, the virtual movements try to create an alternative opinion compared with those cast by mainstream media. For example, in The Power of Identity, scholar Castells [1] tells of how a Mexican nationalist movement organization, Zapatistas, successfully used a fax and Internet-based world alliance to bring the issue of social exclusion and political corruption to the eyes and ears of world public opinion. Sustaining the prolonged development of social movement is the main function because of employing information technologies employed. As Fortier insists:

By now, and despite the strength of mainstream media, they continue to provide alternative information, crucial to the logistics of progressive movements. Most important for the overall political balance, and through technological appropriation, different forms of ICTs and networks can more widely provide critical and alternative analysis, loosen information flows, and resist against pervasive surveillance [13].

Secondly, hyper-linking or associating a movement's goal with the common interest of media is an effective way to create "virtual" movements' narrative basis. For instance, as a result of connecting with the out-group public, the virtual movement can reach its potential supporters. Diani [14] indicates, " the most likely outcome of the introduction of CMC is the conversion of dispersed communities of sympathizers into virtual communities with a slightly higher degree of interaction"(p.123). Moreover, due to high-capacity communication technologies, people reconnect themselves with visual materials; as a result, the legitimacy of the consumerism of mass media in capitalism societies will be challenged by virtual movements' visual text. As Tambini mentions:

An ever greater proportion of information for citizenship is carried by for profit broadcasters, which only compounds the critique of society and politics as a sport or a spectacle for sale: what Garnham calls the politics of consumerism and others have called the society of the spectacles, or sound-bite politics. With the rise of new, interactive, and high-capacity media these problems are being reassessed, and the relationship between public, nation, and state (local and national) is being renegotiated [15].

For the sake of explanation, the point of information movement is described in the following section.

In comparison with new social movements and information movement employ different communication strategies to accomplish the social actor's task. For instance, in terms of resources, due to distinctive purposes of connecting people, the information movement tends to enact an "imagined" community. In the information movement section, in terms of generating knowledge, the net movement tends to present the "language" or circulate "video materials" in order to manifest the existence of connection functions. In the category of purpose of action, the information movement group tries to associate with others in the psychological empowerment. For instance, the format of linked photo is employed by the guests and newcomers to show their interest in the movement group. Also, the affective connection becomes the important material basis to invite Web chatters' participation in the Internet [16]. Such emotional contact, furthermore, is a way to set up a mediated community. The main character of information movements, in the purpose of action, seeks to share participants' experiences, which consequently establishes the community.

The research uses the qualitative method to survey the text of virtual movement. First, the researcher jointed a tour of internet space, the PTT (http://www.ptt.cc/), constituted by the baseball fans from May 1 to Oct 31, 2008. In Taiwan, fans usually talks in the BBS while they watch the televised baseball game. In other words, in part, the fans perform the identity by their own ways through the virtual space. For example, fan will say he met a player in a café when the player walks in the strike area. Therefore, the baseball game has been blurred into the fans' threads in the BBS. The T-rex movement means that a social performance has been manoeuvred.

The purpose of trace of virtual community allowed the researcher survey the formation of identity in a natural setting. Second, during the event, the researcher also recorded the response of mainstream media. The data mainly comes from the newspaper columnist and sports television critics. These contents serve as the contextual elements, whereas the virtual movement was situated. Historically, the baseball report is mainly framed by the sports TV professionals because the information about baseball players is hard to convey by fans in Taiwan [17]

Taiwan's baseball industry was established in 1991 furthermore. The Chinese Professional Baseball League (CPBL) is organized by four professional baseball teams. CPBL-media linkage is usually 
Citation: Hsu CY (2015) The Role of Television Video in Emerging a Social Movement: A Study of Information Environment. Int J Journalism Mass Comm 2: 109. doi: http://dx.doi.org/10.15344/2349-2635/2015/109

Page 4 of 6

operated by the cultural elites here. Through the televising sports programs, watching baseball programs seems the most favorite activity among Taiwanese. Let us take the T-Rex event as the example of virtual movement to review how the national imaginary has been readdressed.

In this study, 60 electronic artifacts, stored on the Bulletin Board System (BBS), have been selected as texts representing the participants' movement experiences (Table 1). For studying the emergence of a virtual community, this time period was framed to study six months virtual activities. The research question is: what the purpose of information movement has attained? And, secondly, what is the role of information mobilization has played in, finally, in terms of theoretical concern, how the concept of information mobilization will contribute to the discussion of social movement.

\begin{tabular}{|l|l|l|}
\hline Content & unit & Time \\
\hline Discussion & 60 & May. 1-Oct. 31, 2008 \\
\hline Materials & & \\
\hline
\end{tabular}

Table 1: The text of T-Rex event stored by BBS.

\section{Engaging a social event}

The fans Internet activities actually began with the circulation of television video. People seldom doubt about the performance of baseball players in Taiwan. Taiwanese people believe in the glory of baseball player over the past decades. The national symbol is actually framed by the TV sports elites who know the connections between the imaginary and representations of player on mainstream media. Occasionally, people in Taiwan have fixed the crippled baseball industry in recent two years. The strategy to do so is to raise the questions on some tricky performances that player had made in the mid of 2008. On June 14, 2008, the following message appeared on PTT. In line 3 to 4 , a fan wrote:

Title: $\{$ A question $\}$ When will they freeze A- Bi ,the player? Date: Sat Jun 14 16:00: 192008

To watch Hu Jen Wei(胡仁偉) replaced Kuo Ming Jen(郭銘仁) in the game, I don't see anything but a point shaving.

They kept calling the player whose batting average is under to be in the game, I don't think it is normal. It feels like someone was pointed by a gun, and forced him to arrange a suicidal player list.

What will happen if they freeze $A-B i$, the player? Or making a plan that they regard him is out of discipline, and let him go, and said that he has a problem in order to let the other team to take over him? I think this will violate some people's bottom line.

Actually, they do not allow Kuo Ming Jen to play in the game deliberately that has violated my bottom line. To watching a game of point shaving, and freeze the player who should play in the game, I wish the league will crumble as soon as possible. The explanation from the coach was really unsatisfied, but what really annoyed me is no one has disagreement about that. That is pretty suck. I would rather watch they lessened the player before than the situation like this.

The movement began with some quests raised by fans because they found the tricky plays in the uploaded television materials. Apparently, the fans' discussions angered Shin Jian Chin (施建新) who is the vice president of T-Rex. As usual, Shin declaimed those BBS chatting as rumors or non-sense talks. As a matter of fact, the consequence of mentioning problem is way to define an event from the perspective of social movement [13]. After one month, On July 24th, Shin Jian Chin, T-Rex vice president, committed that he is the person Shiau Shin who used a faked name to manipulate most opinions that fans had posted in the BBS. After the truth released, mainstream media report was posted on the PTT immediately.

China Times " Players plotted a game of point shaving? dmedia T-REX, the team has a clarification to make" July $24^{\text {th }} 08$.

Shin Jian Chin (施建新)had confessed that he is the "Shiau Shin"( 小新) yesterday, and his statement on the PTT arose a concern from the chief officers of CPBL and other baseball teams. So he was asked to clarify why he made statement which harmed the league at last night. When Shin Jian Chin was interviewing, he seemed to be very angry and said "The report from the internet has completely misled my point, and I did not act like what the BBS represented, I never said that players was asked to plot a game of point shaving. I had recorded what I had said, so if you detoured what I said on the paper, I will definitely sue you."

The pattern of information communication is considered as an important factor that has distinguished the information movements from social collective actions. After one month, the Taiwanese virtual movement mainly has employed the Internet as its own communication resource. Instead of ignoring the PTT users' voices, finally, the mass media reported those players who may involve a match fixing scandal.

In response to Shin's announcement, some user replies:

Recommendation(推, or I endorse) $\mathrm{p}^{* * * * * * * *} \mathrm{o}$ : it is really pissing me off to read about his name right now.

$\rightarrow \mathrm{e}^{* * * * * * * *}$ : he deserved it for what he had done.

$\rightarrow \mathrm{Ba}{ }^{* * * * *}$ : Is Shin Jian Chin also under the investigation of the bureau of investigation?

When the event has been initiated, tremendous information mobilization were represented by the word "recommendation" or " 推”. Here, media reporters cover the Internet event by the number of recommendation. The larger number of recommendation makes the Internet event more visible on media space. Instead of viewing the fans' discussion as rumor, the July' report of China Times, a national newspaper, finally stated the movement. In the beginning, Shin condemned the fans' quests as rumors and tried to conceal the match fixing scandals. However, the revelation of unidentified user-Shiau Shin(小新), has legitimized the newsgroup user's claims.

\section{The emotional user}

The purpose of virtual movement launched by the T-Rex fans is to separate the players from the discourses of media-sport business rhetorically, which has distinguished the virtual space from the market of media space. T-Rex baseball team was kidnapped by the local gangster members until the vice president admitted he used a nickname to manage with the quests of fans joined in BBS. After the revelation, BBS attendants learned how the problem of game match could be. The people's perception toward to player begins to reframe. The players are not honest. The passion of baseball lover is hurt again.

The first research question ever asked was about the main purpose 
of verbal actions created by the information movement. In the content survey of replies shown on the BBS the results is primarily related to the category of association. However, only parts of the e-mails are concerned with the debates of sports policy and reforms. The majority of responses are emotional and expressional passages, for instance greeting on the holidays or satires about current political events. In considering the purpose of action, the Taiwanese case demonstrated more emotion-oriented communities. The social identity may keep the members from isolation. Instead of establishing a rational sphere, such space reflects the emotional aggregation of individuals [18].

For instance, in an e-mail, a member replied:

Recommendation $L^{* * *}$ : Took somebody's word serious that is really annoyed.

$\rightarrow t^{* * * * * *}$ : Definitely, you will completely lose if you take local people's (people who like leave commentary on BBS with their own feeling) words seriously.

In another e-mail, KIWI wrote:

Recommendation $A^{* * * * *}$ : it is not the point that whether he took examples or not, the point is he imputed all the controversial statements he made to all baseball fans.

\section{A user wrote:}

Recommendation $C^{* * * *}$ : I don't know what the function of the press conference is. We are not retard. They were acting very impassioning.

From three examples of e-mail, the virtual movement, we may say that fans mobilize the member or supporters in an emotional manner, which is the main character of virtual movements. In a word, such local knowledge is the materialistic basis to co-exist the social collectiveness.

The finding assures the thinking about the issue of emotional connecting in forming a community. In his thought, sociologists indicate that the issue of affectivity, a major dimension of community, functions as re-tribal Internet users into a social collectiveness, which reveals the characteristic of virtual communities [19]. It is evident that the T-rex event produces a social space to extend fans' connections with others. So, even if it is non-membership movement, the identitynetworking process also can be considered social movement as well. Paralleled to the new social movement, the virtual movement actually begins with the bottom-up activities of BBS user' chatting. Therefore, the alliance over individual user is realized through the inter-linking media watching materials shown on the television contents.

\section{Concluding Remarks}

The information environment engulfs the process of spatial practice, in which the imagined community becomes a space for constructing the social collectiveness, where is undermined by the emotional association. In other words, the information mobilization allows a process of performing social identity in terms of framing the everyday's Internet activities. Through the exchange of information, the community of users resists the representation on mainstream media. Hence, the movement performs identity of being baseball lovers through the space. Further, the environment is construed by a process of social interaction.

In detail, visual material is an important component to interpreter the event in the virtual space. If the Internet is the base of the Information
Society, from the perspective of information movement, then a fundamental question is: what is the impact of web users' activities on the construction of community? Scholar Anderson mentions that the symbolic communication is an important character of constructing imagined communities. In this case, in terms of mobility of information, I argue that the role of information environment is to function as event organizer and knowledge sharer as well.

Since the baseball game video material has been streamed into the website, digitalized video circulating on the BBS began to help the attendant to joint the event, finding out the some suspicious play of players. Such information behaviors further made the newsgroup as the media outlet during the time of controversy. In Taiwan, normally baseball discourse is narrated by the media-sports elites. The baseball game worked as cultural imaginary for integrating people in the past decades. By video clips circulating on the virtual space, the movement actually won people's imagination, on which continues the affective outbreak for information mobilization.

In evidence, the virtual community has deflected the symbol of baseball player by setting up the base of reasoning. In this case, contrary to media elites, the Web user tries to sketch the image of a baseball fans. The purpose of virtual movement is to set up emotional connection where functions as a cultural access of imagined community. In the process of social interaction, the sense of belonging is realized by the information environment which is constructed by the visualtext event. Therefore, comparing with the media space, the Internet becomes the alternative space by exercising the process of pluralizing the knowledge into a local dense. For De Certeau [20], in book practice of everyday life, his concept inspires the concept of registering knowledge in people's own end of everyday's life. He mentions that the increasingly common expectation that experts should speak in the public, non-specialists domain to popularize, to be accessible, to disseminate, to be accountable inevitably results in a loss of expertise. The Internet becomes an unique space for pluralizing knowledge in a cultural enclave, which is aura with culture in expressing the identity of being Taiwanese.

In sum, the media elite is losing the legitimacy over the nation's myth due to the social engagement launched by the information mobilizations. The process of information mobilization set up a frame of event; therefore, the user gains the affective resource to generate the social collectiveness. The process of virtual community is fertilized by cultural imaginations. According to findings I mentioned, I argue that the information environment constitutes an alternative space in a society, where allows people's voice that juxtapose with the statismthe elite's discourses.

Cultural event, thus, characterizes a feature of everyday practice, since they are fundamentally about reflecting and acting upon people, their conditions of existence and their social practices [21]. In terms of the concept of every day's practices, the social drama of movement in the virtual association creates the virtual communities. In the context of interpretative community, the web visual materials can be understood as mobilizing resources that initiated information movement. In other words, the environment of visual materials calls a network of being baseball fans. The findings of this case study reciprocate with theoretical assumption of imagined communities proposed by scholar Anderson. In this case, I argue, the case has shown that knowledge sharer seeks to make social collectiveness, which has sketched the environment of community [6]. 
Citation: Hsu CY (2015) The Role of Television Video in Emerging a Social Movement: A Study of Information Environment. Int J Journalism Mass Comm 2: 109. doi: http://dx.doi.org/10.15344/2349-2635/2015/109

Page 6 of 6

Whilst not a social movement as sociologists tends to use the term, I see the collective response to T-Rex scandal as an instance of collective action and mobilization which expressed social movement, in the sense of social, cultural and political change. The baseball fans' image of this virtual event could be embedded in the ordinary knowledge which is different from the nobody stereotype of fan whom has been represented by media elites for years.

In Taiwan, media elite had over amplified the stardom of players to integrate the social norms of rural people since the government began to develop the island economy in 1960s. This dominance of discourse has been transplanted into the sports business when CPBL establishes in 1991 [22]. The image of baseball player has been constructed by sport-media linkage to publicize the legitimacy of Statism, which may overshadow the business. In other words, the image of baseball players in fact is constructed for the purpose of integrating the separate ethnic people rural Taiwanese, mainland Chinese and aboriginals. Without a political declaration, virtual mobilization just is a quest on such official discourse, and the community they set up is a place of emotional contact.

In terms of reconsidering the role of information in social movement theories, based on findings above, I argue that the information mobilization refuges a space in performing the identity of cultural symbol that is away from the dominance of news media. By the usage of ordinary information, in terms of the future of public media, such new identity had transgressed the "banal" national incursion of media elites' discourses [23]. In theoretical concept, the theoretical element of information environment may shed light on the social movement study. As Nash indicated, the social morphology of the Information Age is networks organized around information flows. There is an unprecedented fluidity and flexibility in social arrangement [24]. In empirical, I find the movement performed by the information mobilization originates an imagined community, in where has interweaved the information flows with identity relevant objects.

\section{Competing Interests}

The author have declared that no competing interests exist.

\section{References}

1. Castells M (1997) The power of identity. London: Blackwell.

2. Washbourne N (2001) Information Technology and new forms of Organizing?

3. Coleman $S$ (1999) Cutting out the middle man: from virtual representation to direct deliberation. In Nague BN and Loader BD (Eds) Digital Democracy: Discourse and Decision Making in the Information Age (pp. 195-210) New York: Routledge.

4. Pickerill J (2001) Weaving a green web: environmental protest and computer-mediated communication in Britain. In Webster F (Ed), Culture and politics in the Information Age. (pp.142-167). New York: Routledge.

5. Sypher HE \& Collins B (2001) Virtual-online communities: How might new technologies be related to community? In Shepherd GJ and Rothenbuhler EW (Eds), Communication and Community. (pp. 191-200). New Jersey: LEA Publishers.

6. Anderson B (1991) Imagined communities: reflections on the origin and spread of nationalism. London: Verso.

7. Frankel B (1994) Class, environmental and social movements. In Geertz C (Ed) The polity reader in social theory. (pp.321-326). London: Blackwel Publisher.
8. Peteet J (2000) Refugees, resistance, and identity. In Guidry J, Kennedy M, and Zald M (Eds), Globalization and social movements. (pp.183-209). Michigan: University of Michigan Press.

9. Bagguley P (1999) Beyond emancipation? the reflexivity of social movements. In O'Brien M, Penna S, and Hay C, (Eds) Theorizing Modernity (pp.65-82). New York: Longman.

10. Mitra A (2001) Marginal voices in Cyberspace. New Media and Society 3: 29-48.

11. Bakardjeiva M, Smith $R$ (2001) The Internet in everyday life The Internet in everyday life. New Media and Society 3: 67-83.

12. Sy $P$ (2001) Barangays of IT Filipinizing mediated communication and digital power. New Media and Society 3: 296-312.

13. Fortier $F(2000)$ Virtual communities, real struggles: Seeking alternatives for democratic networking. In Gurstein M (Ed), Community Informatics: Enabling Communities with Information. (pp.446-469). London: Idea Group Publishers.

14. Diani M (2001) Social movement networks: Virtual and real. In Webster, F. (Ed), Culture and politics in the Information Age. (pp.117-128). New York: Routledge.

15. Tambini D (2001) The civic networking movement: the Internet as a new democratic public space? In Crouch $C$, Eder K, and Tambini D (Eds), Citizenship, Markets, and the State. (pp.238-270). Oxford: Oxford University Press.

16. Russell A (2005) Myth and the Zapatista movement: exploring a network identity. New Media and Society 7: 559-577.

17. Chen, wenshiang (2010) Constructing an image of baseball player: the case of Chingming Wang. Unpublished Master Thesis. Taipei: Tamkang University.

18. Roseneil S (2001) A moment of moral remaking: the death of Diana, Princess of Wales. In In F. Webster (Ed) Culture and politics in the Information Age. (pp.96-114). New York: Routledge.

19. Maffesoli M (1996) The time of the tribes: the decline of individualism in mass society. London: Sage.

20. De Certeau M (1984) The practice of everyday life. Berkley, CA: California University Press.

21. Turner V (1974) Drama, fields and metaphor: symbolic action in human society. Ithaca: NY: Cornell University Press.

22. Chen SY (1998) State, media and democracy in Taiwan. Media, Culture and Society 20: 11-29.

23. Stevenson $N(2001)$ The future of public media. In Webster $F(E d)$ Culture and politics in the Information Age. (pp.63-80). New York: Routledge.

24. Nash K (2001) Contested power: political sociology in the Information Age. In F. Webster (Ed), Culture and politics in the Information Age. (pp.81-95) New York: Routledge. 